\title{
CLONAGEM POR TRANSFERÊNCIA NUCLEAR EM BUBALINOS
}

Aline Sousa Camargos ${ }^{1}$, Ariane Dantas ${ }^{2}$

${ }^{1}$ Docente do Departamento de Zootecnia, Instituto Federal Goiano, Campus Morrinhos, e-mail: alinescamargos@gmail.com, ${ }^{2}$ Doutora em Biotecnologia Animal, Departamento de Reprodução Animal e Radiologia Veterinária, Faculdade de Medicina Veterinária e Zootecnia, Unesp, Botucatu.

\section{RESUMO}

O sucesso da transferência de núcleo (TN) depende da origem da célula doadora, do estágio de desenvolvimento do citoplasto receptor e da sincronia entre o ciclo celular da célula doadora de núcleo com a receptora. O núcleo somático deverá ser reprogramado após a TN, restaurando assim o estado totipotente, para então retomar o desenvolvimento celular. Contudo, observa-se que a eficiência da TN ainda é baixa, fato esse, relacionado principalmente com a deficiência da expressão genética global do embrião clonado. No entanto, o número de espécies de mamíferos clonados vem aumentando nos últimos anos, sendo essa técnica, uma importante ferramenta no auxílio da efetividade da reprodução de bubalinos. Desse modo, esta revisão centra-se na descrição dos principais mecanismos pertinentes à realização dessa técnica, além de discutir as implicações futuras, bem como certos fatores que afetam o sucesso da transferência nuclear.

Palavras-chaves: biotecnologia, clonagem animal, reprogramação nuclear

\section{CLONING BY NUCLEAR TRANSFER IN BUFFALOES}

\begin{abstract}
The success of core transfer (CT) depends on the origin of the donor cell, on the stage of development of the recipient cytoplast and on the synchronization between the cell cycle of the donor and recipient cells. The somatic nucleus must be reprogrammed after $\mathrm{CT}$, thus restoring the totipotent state, and then resuming cellular development. However, it is noted that the efficiency of CT is still low, especially with a deficiency of the overall gene expression of the cloned embryo. However, the number of species of cloned mammals has been increasing in the last years, being this technique an important tool that does not aid in the effectiveness of buffalo reproduction. Thus, this review focuses on the description of the main processes pertinent to this process, as well as to analyze as future implications, as well as some factors that affect the success of nuclear transfer.
\end{abstract}

Keywords: biotechnology, animal cloning, nuclear reprogramming

\section{INTRODUÇÃO}

A transferência nuclear (TN) baseia-se na capacidade única dos citoplastos de oócitos detidos pela metafase II em converter núcleos de células somáticas transplantados por eletrofusão para se tornarem capazes de reverter completamente de estágios diferenciados para a totipotência (LOI et al., 2016).

Os primeiros registros do uso dessa técnica em bubalinos são relativamente recentes na literatura veterinária, sendo o primeiro relato científico descrito por de Shi et al. (2007), os quais observaram a possibilidade de utilização de fibroblastos fetais ou células da granulosa como células doadoras de núcleo em três bezerras clonadas. 
O sucesso dessa pesquisa foi atribuído ao método de enucleação não-invasiva que foi empregado pelo sistema de visualização do eixo, assegurando a formação de citoplastos de qualidade; a utilização do soro de afidicolina plus sem suplementação para sincronização do ciclo das células doadora a fase G0/G1 sem danos ao genoma nuclear em comparação ao soro sem suplementação e à aplicação do método de eletrofusão para fundir célula doadora e citoplasto em que uma alta taxa de fusão pode ser obtida com uma intensidade relativamente baixa de campo elétrico (SHI et al., 2007).

Embora a atual taxa de sucesso na produção de animais vivos por clonagem seja baixa (CIBELLI et al., 2014), bons resultados foram alcançados com o avanço na área de clonagem de bubalinos (MADHESHIYA et al., 2015), proporcionando dessa forma, a ampliação nas áreas de conservação e melhoramento genético, produção de indivíduos transgênicos dessa espécie, bem como a produção de animais com genética ou resistência superiores a doenças, conferindo mais resistência, qualidade e consistência aos seus produtos (WILMUT et al., 2015).

Contudo, ressalta-se, que as informações obtidas até o presente momento, sobre epigenética e reprodução assistida ainda são insuficientes (HOSSEINI et al., 2016), sendo necessário a realização de mais estudos, principalmente sobre os fundamentos e mecanismos do processo em geral, para que assim, a técnica da clonagem nessa espécie, possa ser aplicada em escala comercial.

O objetivo deste trabalho foi realizar uma revisão de literatura sobre clonagem por transferência nuclear, abordando principalmente os procedimentos técnicos utilizados, suas aplicações e impactos potenciais na bubalinocultura, além de identificar relatos atuais na literatura sobre esse assunto.

\section{METODOLOGIA GERAL DA TÉCNICA DE CLONAGEM POR TRANSFERÊNCIA DE NÚCLEO}

O método poderá se concretizar nas diversas etapas ou passos que serão descritos na sequência, servindo de guia para o estudo sistemático do enunciando.

\section{- $\quad$ Material usado como fontes da técnica}

O oócito é o material de estudo utilizado na realização da técnica de TN podendo ser esse oriundo de ovários de animais vivos ou mais comumente de animais abatidos. Nesse caso os cuidados quanto asseguração da qualidade dos oócitos devem ser elevados.

A qualidade do oócito é um fator crítico para a ativação e desenvolvimento dos embriões. Em bubalinos, os oócitos ou complexos de cúmmulus oócitos com multicamada de células do cúmulus intacta e ooplasma granular homogêneo são indicados como os materiais mais sugeridos para a realização de pesquisas sobre esse tema (YADAV et al., 2010).

\section{- $\quad$ Enucleação}

A enucleação tem por objetivo manter a ploidia dos organismos que serão clonados. A derivação de citoplastos viáveis através de enucleação química é um método aceito para a produção de embriões clones, e tem sido aplicada em animais de fazenda, como: cabras, vacas e búfalas (PEREIRA et al., 2013, IWAMOTO et al., 2015, SAIN et al., 2015). Deve-se enfatizar que a indução da enucleação feita na meiose II pode ser ativada por uma breve exposição dos oócitos pré-ativados à demecolcina (SARAIVA et al., 2009).

As abordagens recentes da enucleação química são baseadas no fenômeno onde o tratamento da fase M II com agentes relaxantes do citoesqueleto que induzem uma extrusão sobre a superfície do citoplasma do oócito facilita a remoção de material genético por aspiração mecânica ou bipartição manual dos oócitos livres de zona pelúcida (KEEFER et al., 2015). 
Ressalta-se que nos oócitos bubalinos, os cones de extrusão induzidos pela demecolcina são mais proeminentes e acessíveis para remoção na maioria dos oócitos, seja eles com ou sem zona pelúcida (YADAV et al., 2010).

\section{- $\quad$ Preparação dos citoplastos}

A preparação de um citoplasto consiste na remoção do genoma nuclear de um oócito e a substituição do seu material nuclear por um núcleo de uma célula somática, com o mínimo de perturbação possível. Em bubalinos, os complexos cúmulus oócitos imaturos maturados in vitro por 20-22h, com células do cúmulus uniformemente expandidas e de superfície ancorada podem ser usadas para o preparo dos citoplastos (SINGH, 2006).

Os oócitos que apresentam o primeiro corpúsculo polar são desnudos por striped-off ou pelo tratamento com tripsina, seguido de suave micropipetagem. A enucleação é feita por micromanipuladores acoplados a um microscópio invertido (PEREIRA e FREITAS, 2009).

Acredita-se que a enucleação induzida por demecolcina possa ser uma técnica promissora na preparação dos citoplastos (SHAH et al., 2008). TANI et al. (2006), em estudo realizado com oócitos de bovinos tratados com demecolcina por 30 minutos, obteve a produção de uma membrana a qual facilitou a enucleação sem prejuízos sobre a competência dos oócitos e desenvolvimento dos clones após o nascimento, indicando que a remoção nuclear dos cromossomos por tratamento químico é efetiva no preparo de citoplastos.

A importância dessa fase para o sucesso do processo de clonagem tem despertado o interesse comercial de várias empresas, sendo possível encontrar disponível no mercado diversos sistemas com softwares que permitem a identificação dos citoplastos e confirmação da enucleação pela observação do eixo extraído, aumentando assim a confiabilidade do processo.

\section{- Seleção da célula doadora}

A seleção da célula doadora é um critério importante na determinação da eficiência do animal clonado. Teoricamente, qualquer célula somática pode ser cultivada e utilizada como célula doadora, necessitando apenas ser, antecipadamente, cultivadas e preparadas especificamente antes da fusão com o citoplasto (DO e TAYLOR-ROBINSON, 2014). No entanto, algumas células como células tronco embrionárias, células da granulosa, células do cúmulus e células somáticas fetais são indicadas como as melhores doadoras, devido a sua maior habilidade na reprogramação após a transferência para o citoplasto (VERMA et al., 2015).

Com o aprimoramento do método TN a quantidade necessária a ser utilizada como doadoras nucleares diminuiu drasticamente. Embora a taxa atual de sucesso da clonagem de animais não seja elevada, os procedimentos de clonagem continuaram a evoluir surgindo novos métodos e produtos, dentre os quais podemos citar: a adição de inibidores da histona desacetilase ao meio (SHINAGAWA et al., 2014). Outros tratamentos específicos incluem principalmente o uso do soro sem nutrientes, todavia, existe a possibilidade do uso de certos agentes tais como: a tricostatina A, citocalasina B, ou rocosvitina (INOUE et al., 2015). Contudo, não há relato da adequação destes métodos em todas as espécies.

Os primeiros estudos envolvendo a produção de embriões clonados em bubalinos, utilizaram os fibroblastos fetais como material para produção de embriões clonados. Posteriormente, houve a descoberta de que as células da granulosa também poderiam ser reprogramadas e utilizadas na para produção de embriões clonados nessa mesma espécie (YADAV et al., 2010).

\section{- $\quad$ Eletrofusão de células doadoras de núcleo para o citoplasto}

A eletrofusão é a interação de ondas AC e DC produzidas por equipamento especializado que tem como finalidade a promoção da fusão de células doadoras. Representa uma etapa crítica 
da clonagem por TN, visto que a eficiência desse procedimento em células somáticas com citoplasma, é considerado fator limitante do sucesso da clonagem (TRECENTI e ZAPPA, 2013).

Os dísticos são posicionados entre os eletrodos na câmara de fusão, enquanto o processo é visualizado por um microscópio estereoscópico. Deve-se tomar o cuidado em colocar as célulascitoplastos em um plano perpendicular para que as ondas AC induzam a eletroporação das células. Com apenas 1 microsegundo de transição de AC para DC, obtém-se uma fusão eficiente. Após a fusão, a reaplicação de AC mantém as células unidas (BORDIGNON, 2008).

\section{- $\quad$ Cultivo in vitro dos embriões clonados}

Antes de iniciar essa etapa, é necessário, antes, avaliar a viabilidade das células recémconstruídas, sendo que somente aquelas em divisão ativa são as serão cultivadas. Uma vez cultivadas, os embriões são então transferidos quando atingirem o estágio de blastocisto (MOHAPATRA et al., 2015).

É a combinação de meios e condições ótimas de cultura que permitem com que o sucesso desse processo técnico seja alcançado. Para o cultivo in vitro dos embriões pode ser utilizado meios preparados em laboratórios ou comprados prontos. Baseado nos relatos científicos de produção de embriões clonados, os meios de cultura Charles Rosenkrans 2 - aminoácidos (CR2aa) e o Synthetic Oviduct Fluid (SOF) são os utilizados com maior frequência na promoção do crescimento dos embriões in vitro (SHI et al., 2007). Lembrando que o meio de cultura deve ser então filtrado, esterilizado e pode ser estocado a 4 으 $\mathrm{C}$ por até 4 semanas.

\section{- $\quad$ Sincronização de estro e transferência de embriões clonados}

A sincronização de estro consiste no agendamento do estro de um grupo de receptoras com as doadoras que foram superovuladas pela administração de drogas exógenas. A escolha do animal receptor deve levar em consideração o seu status corporal e reprodutivo (MOGOLLÓNWALTERO et al., 2014).

Para a realização da sincronização, são administradas drogas como a prostaglandinas e a gonadotrofinas. Contudo, ressalta-se que a eficácia das drogas e a eficiência dos protocolos podem variar dependendo do tempo de aplicação, estado fisiológico e nutricional dos animais utilizados no procedimento (YADAV et al., 2010).

Os embriões são transferidos para as receptoras, mas o nascimento do clone vai depender de vários fatores, tais como: a expressão correta de genes associados à pluripotência no início e após o período de implantação, a saúde da receptora, manejo e cuidado neonatal (PRIYA et al., 2014).

\section{OPORTUNIDADES E PERSPECTIVAS FUTURAS}

O progresso observado nas pesquisas na área de clonagem é importante tanto para o veterinário, produtor, como para fins científicos e comerciais, pois bons resultados na criação de animais dependem da correta aplicação de conhecimentos práticos alicerçados em princípios teóricos básicos e no bom uso de práticas biotecnológicas (OGURA et al., 2013).

Dessa forma, a clonagem apresenta-se como uma importante ferramenta de conservação e regeneração da biodiversidade (recursos genéticos), transgenia, produção animal e terapêutica. Sendo o número de estudos sobre as alterações fisiológicas, anatômicas e funcionais ainda insuficiente (LAGUTINA et al., 2013).

Assim, apesar dos bons resultados alcançados nos últimos anos, umas das principais causas da baixa eficiência da técnica de transferência nuclear de células somáticas, são as anomalias evidenciadas na expressão de genes impressos, comprometendo assim a eficiência do procedimento (SMITH et al., 2012). Observou-se, com frequência, altas taxas de perdas embrionárias, mortinatos, mortalidade pós-natal e anormalidades neonatais, devido, 
particularmente, à diminuição da capacidade do oócito de redefinir a memória diferenciada de uma célula somática (WATANABE et al., 2013; HILL et al., 2014). Nesse sentido, uma boa seleção e pré-tratamento das células doadoras e o uso do meio de cultura e técnica ideais durante o estágio de pré-implantação podem otimizar a tecnologia para aplicações na produção de bubalinos.

\section{CONSIDERAÇÕES FINAIS}

A clonagem é uma ferramenta valiosa que, se bem conduzida, pode otimizar diversos programas reprodutivos proporcionando em reduzidos intervalos de gerações, a ampliação do uso de genótipos para produção de sêmen e embriões. Aumentando dessa forma oportunidades de cruzamento, bem como a diminuição da perda de animais com características desejáveis.

Contudo, devido à complexidade das várias etapas requeridas para reconstrução de oócitos por transferência nuclear, novos protocolos são necessários com a finalidade de minimizar os danos durante as manipulações e aumentar a habilidade de reprogramação.

\section{REFERÊNCIAS}

BORDIGNON, V. IN: GONSALVES, P.B.D.; FIGUEIREDO, J.R.; FREITAS, V.J.F. Biotecnologias aplicadas à reprodução. 2. ed. São Paulo: Roca. 2008. p.347-365.

CIBELLI, J.; WILMUT, I.; JAENISCH, R.; GURDON, J.; LANZA, R.; WEST, M.; CAMPBELL, K. Principles of Cloning. 2. ed. Netherlands: Academic Press - Elsevier. 2014. 572p.

DO, V.H.; TAYLOR-ROBINSON, A.W. Somatic Cell Nuclear Transfer in Mammals: Reprogramming Mechanism and Factors affecting Success. Cloning and Transgenesis, v.3, n.3, p.1-5, 2014. https://doi.org/10.4172/2168-9849.1000129

HILL, J.R. Incidence of abnormal offspring from cloning and other assisted reproductive technologies. Annual Review of Animal Biosciences, v.2, p.307-321, 2014. https://doi.org/10.1146/annurev-animal-022513-114109.

HOSSEINI, S.M.; DUFORT, I.; NIEMINEN, J.; MOULAVI, F.; GHANAEI, H. R.; HAJIAN, M.; JAFARPOUR, F.; FOROUZANFAR, M.; GOURBAI, H.; SHAHVERDI, A. H.; NASR-ESFAHANI, M. H.; SIRARD, M. A. Epigenetic modification with trichostatin $A$ does not correct specific errors of somatic cell nuclear transfer at the transcriptomic level; highlighting the non-random nature of oocyte-mediated reprogramming errors. BMC Genomics, v.17, n.16, p.1-21, 2016. https://doi.org/10.1186/s12864$\underline{015-2264-z}$

IWAMOTO, D.; YAMAGATA, K.; KISHI, M.; HAYASHI-TAKANAKA, Y.; KIMURA, H.; WAKAYAMA, T.; SAEKI, K. Early development of cloned bovine embryos produced from oocytes enucleated by fluorescence metaphase II imaging using a conventional halogen-lamp microscope. Cellular Reprogramming, v.17, n.2, p.106-114, 2015. https://doi.org/10.1089/cell.2014.0086.

INOUE, K.; OIKAWA, M.; KAMIMURA, S.; OGONUKI, N.; NAKAMURA, T.; NAKANO, T.; ABE, K.; OGURA, A. Trichostatin A specifically improves the aberrant expression of transcription factor genes in embryos produced by somatic cell nuclear transfer. Scientific Reports - Nature, v.5, p.112, 2015. https://doi.org/10.1038/srep10127.

KEEFER, C.L. Artificial cloning of domestic animals. Proceedings of the National Academy of Sciences, v.112, n.29, p.8874-8878, 2015. https://doi.org/10.1073/pnas.1501718112. 
LOI, P.; LUSO, D.; CZERNIK, M.; OGURA, A. A New, Dynamic Era for Somatic Cell Nuclear Transfer? Trends in Biotechnology, v.34, p.791-797, 2016. https://doi.org/10.1016/j.tibtech.2016.03.008

LAGUTINA, I.; FULKA, H.; LAZZARI, G.; GALLI, C. Interspecies somatic cell nuclear transfer: advancements and problems. Cellular Reprogramming, v.15, n.5, p.374-384, 2013. https://doi.org/10.1089/cell.2013.0036.

LI, J.; DU, Y.; ZHANG, Y.H.; KRAGH, P.M.; PURUP, S.; BOLUND, L.; YANG, H.; XUE, Q.Z.; VAJTA, G. Chemically assisted handmade enucleation of porcine oocytes. Cloning Stem Cells, v.8, n.4, p.241250, 2006. https://doi.org/10.1089/clo.2006.8.241

MADHESHIYA, P.K.; SAHARE, A.A.; JYOTSANA, B.; SINGH, K.P.; SAINI, M.; RAJA, A.K.; KAITH, S., SINGLA, S.K.; CHAUHAN, M.S.; MANIK, R.S.; PALTA, P. Production of a Cloned Buffalo (Bubalus bubalis) Calf from Somatic Cells Isolated from Urine. Cell Reprogram, v.17, n.3, p.160-169, 2015. https://doi.org/10.1089/cell.2014.0097.

MOGOLLÓN-WALTERO, E.M.; MELLO, M.R.B.; DÍAS, A.J.B. Clonagem de embriões bovinos a partir de células somáticas. Orinoquia, v.18, n.1, p.95-104, 2014. https://doi.org/10.22579/20112629.285

MOHAPATRA, S.K.; SANDHU, A.; NEERUKATTU, V.S.; SINGH, K.P.; SELOKAR, N.L.; SINGLA, S.K.; CHAUHAN, M.S.; MANIK, R.S.; PALTA, P. Buffalo Embryos Produced by Handmade Cloning from Oocytes Selected Using Brilliant Cresyl Blue Staining Have Better Developmental Competence and Quality and Are Closer to Embryos Produced by In Vitro Fertilization in Terms of Their Epigenetic Status and Gene Expression Pattern. Cellular Reprogramming, v.17, n.2, p.141-150, 2015. https://doi.org/10.1089/cell.2014.0077

OGURA, A.; INOUE, K.; WAKAYAMA, T. Recent advancements in cloning by somatic cell nuclear transfer. Philosophical Transactions of the Royal Society B: Biological Science, v.368, p.1-12, 2013.

PEREIRA, A.F.; FREITAS, V.J.F. Clonagem em ruminantes: progressos e perspectivas atuais. Revista Brasileira de Reprodução Animal, v.33, n.3, p.118-128, 2009.

PEREIRA, A.F.; FELTRIN, C.; ALMEIDA, K.C.; CARNEIRO, I.S.; AVELAR, S.R.G.; ALCÂNTARA NETO, A.S.; SOUSA, F.C.; MELO, C.H.S.; MOURA, R.R.; TEIXEIRA, D.I.A.; BERTOLINI, L.R.; FREITAS, V.J.F.; BERTOLINI, M. Analysis of factors contributing to the efficiency of the in vitro production of transgenic goat embryos (Capra hircus) by handmade cloning (HMC). Small Ruminant Research, v. 109, n.3, p. 163-72, 2013. https://doi.org/10.1016/i.smallrumres.2012.07.020

PRIYA, D.; SELOKAR, N.L.; RAJA, A.K.; SAINI, M.; SAHARE, A.A.; NALA, N.; PALTA, P.; CHAUHAN, M.S.; MANIK, R.S.; SINGLA, S.K. Production of Wild Buffalo (Bubalus arnee) Embryos by Interspecies Somatic Cell Nuclear Transfer Using Domestic Buffalo (Bubalus bubalis) Oocytes. Reproduction in Domestic Animals, v.49, n.2, p.343-351, 2014. https://doi.org/10.1111/rda.12284.

SAINI, M.; SELOKAR, N.L.; RAJA, A.K.; SAHARE, A.A.; SINGLA, S.K.; CHAUHAN, M.S.; MANIK, R.S.; PALTA, P. Effect of donor cell type on developmental competence, quality, gene expression, and epigenetic status of interspecies cloned embryos produced using cells from wild buffalo and oocytes from domestic buffalo. Theriogenology, v.84, n.1, p.101-108, 2015. https://doi.org/10.1016/i.theriogenology.2015.02.018. 
SARAIVA, N.Z.; PERECIN, F.; MÉO, S.C.; FERREIRA, C.R.; TETZNER, T.A.; GARCIA, J.M. Demecolcine effects on microtubule kinetics and on chemically assisted enucleation of bovine oocytes. Cloning Stem Cells, v.11, n.1, p.141-152, 2009. https://doi.org/10.1089/clo.2008.0044.

SHAH, R.A.; GEORGE, A.; SINGH, M.K.; KUMAR, D.; CHAUAN, M.S.; MANIK, R.S.; PALTA, P.; SINGLA, S.K. Hand-made cloned buffalo (Bubalus bubalis) embryos: comparison of different culture media and culture systems. Cloning Stem Cells, v.10, n.4, p. 435-442, 2008. https://doi.org/10.1089/clo.2008.0033.

SHI, D.; LU, F.; WEI, Y.; CUI, K.; YANG, S.; WEI, J.; LIU, Q. Buffalos (Bubalus bubalis) cloned by nuclear transfer of somatic cells. Biology of Reproduction, v.77, n. 2, p.285-291, 2007. https://doi.org/10.1095/biolreprod.107.060210.

SINGH, A.K. Studies on handmade cloning in buffaloes. 2006. Tese de doutorado - Dairy Science College, National Dairy Research Institute, Karnal, 2006.

SMITH, L.C.; SUZUKI, J.JR.; GOFF, A.K.; FILION, F.; THERRIEN, J.; MURPHY, B.D.; KOHAN-GHADR, H.R.; LEFEBVRE, R.; BRISVILLE, A.C.; BUCZINSKI, S.; FECTEAU, G.; PERECIN, F.; MEIRELLES, F.V. Developmental and epigenetic anomalies in cloned cattle. Reproduction in Domestic Animals, v.47, n.4, p.107-114, 2012. https://doi.org/10.1111/j.1439-0531.2012.02063.x.

SHINAGAWA, T.; TAKAGI, T.; TSUKAMOTO, D.; TOMARU, C.; HUYNH, L.M.; SIVARAMAN, P.; KUMAREVEL, T.; INOUE, K.; NAKATO, R.; KATOU, Y.; SADO, T.; TAKAHASHI, S.; OGURA, A.; SHIRAHIGE, K.; ISHII, S. Histone variants enriched in oocytes enhance reprogramming to induced pluripotent stem cells. Cell Stem Cell, v.14, n.2, p.217-227, 2014. https://doi.org/10.1016/j.stem.2013.12.015.

TANI, T.; SHIMADA, H.; KATO, Y.; TSUNODA, Y. Demecolcine-assisted enucleation for bovine cloning. Cloning Stem Cells, v.8, n.1, p.61-66, 2006. https://doi.org/10.1089/clo.2006.8.61.

TRECENTI, A.S.; ZAPPA, V. Clonagem animal: Revisão de literature. Revista Científica Eletrônica de Medicina Veterinária, v.11, n.20, p.1-30, 2013.

VAJTA, G.; MADDOX-HYTTEL, P.; SKOU, C.T.; TESIRLIOGLU, R.T.; PEURA, T.T.; LAI, L.; MURPHY, C.N.; PRATHER, R.S.; KRAGH, P.M.; CALLESEN, H. Highly efficient and reliable chemically assisted enucleation method for handmade cloning in cattle. Reproduction Fertility and Development Journal, v.17, n.8, p.791-797, 2005. https://doi.org/10.1071/RD05066

VERMA, G.; ARORA, J.S.; SETHI, R.S.; MUKHOPADHYAY, C.S.; VERMA, R. Handmade cloning: recent advances, potential and pitfalls. Journal of Animal Science and Biotechnology, v.43, n.6, p.1-10, 2015. https://doi.org/10.1186/s40104-015-0043-y.

WATANABE, S. Effect of calf death loss on cloned cattle herd derived from somatic cell nuclear transfer: clones with congenital defects would be removed by the death loss. Animal Science Journal, v.84, n.9, p.631-638, 2013. https://doi.org/10.1111/asj.12087. 
WILMUT, I.; BAI, Y.; TAYLOR, J. Somatic cell nuclear transfer: origins, the present position and future opportunities. Philosophical Transactions of the Royal Society B: Biological Science, v.370, p.141-150, 2015. https://doi.org/10.1098/rstb.2014.0366.

YADAV, P.S.; SINGH, B.; SINGH, I.; SETHI, R.K. Somatic cell nuclear transfer. In: Reproductive biotechnology in buffalo. New Delhi: Satish Serial Publishing House. 2010. p.85-103. 